\title{
Possibilities to compare graffiti with handwriting
}

\author{
WALTER BRANDNER \\ Certified Court Expert for Handwriting \\ Vienna, Austria
}

At first — it is only a funny example — I inform you about a mysterious case. Yesterday in the evening I watched a sprayer, who wrote this graffiti on the wall of the university:

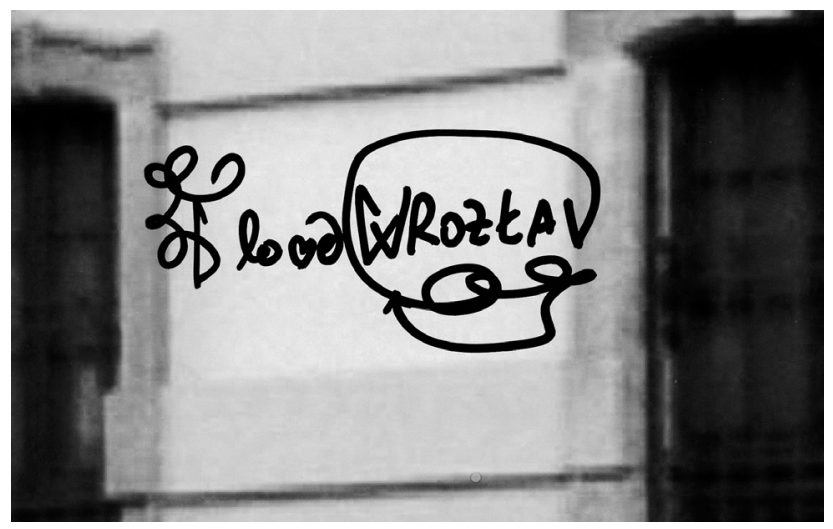


I made a photo of the graffiti and forced the man to give me an example of his handwriting.

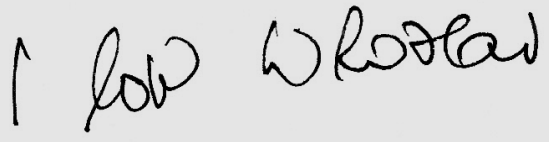

I know that both scriptures are written by the same person, but can I prove it with the methods of forensic handwriting examinations? I will answer this at the end of my presentation.

Graffitis are very old; they had been scratched in walls and trees and more. Today the writers usually use a spray and are called sprayers. This example is from Pompeii.

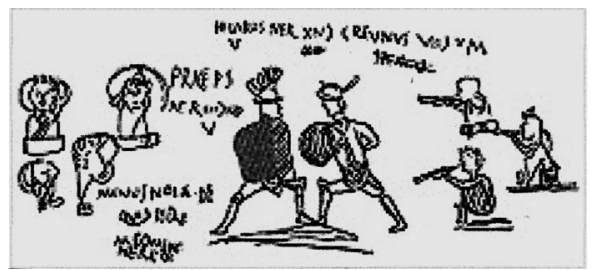

Graffitis of this kind cannot be compared with handwritings. Nevertheless, there are graffitis in the kind of street art, these are pictures.
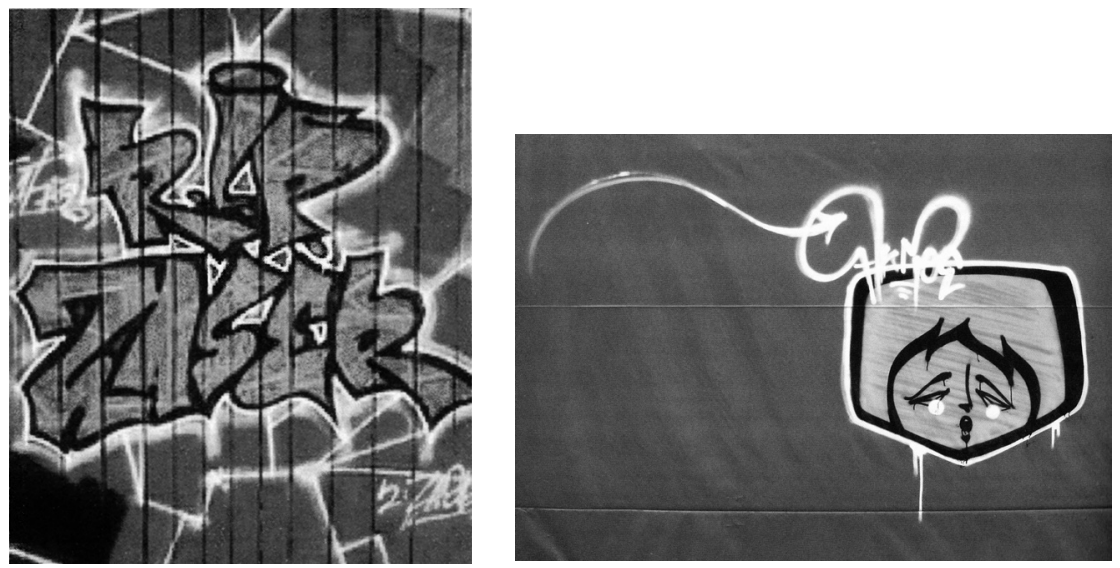

Nowa Kodyfikacja Prawa Karnego 45, 2017

(C) for this edition by CNS 
If a sprayer wants to say "I was here", he produces a tag, this can be a symbol or a name, usually a pseudonym.
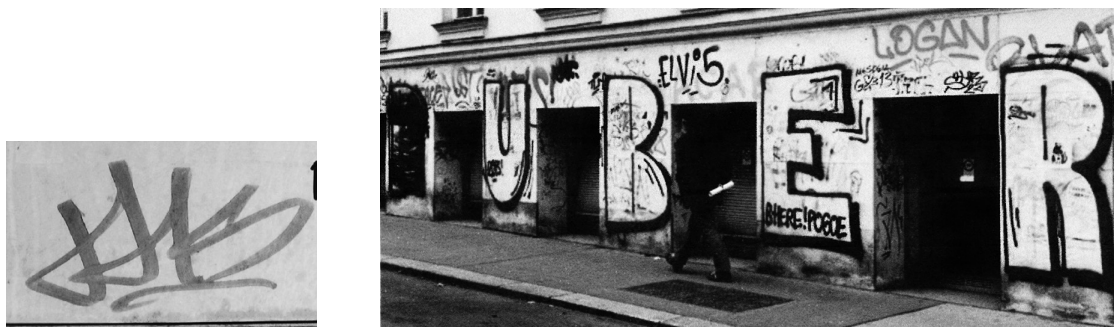

Such tags are written in a calligraphic form and usually they are not similar to the handwriting.

By comparing a lot of tags you will recognise that some tags are very similar. Have these tags been written by one person?
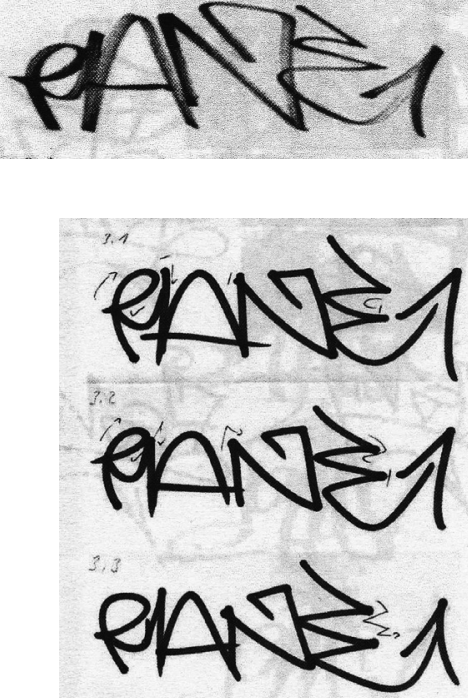
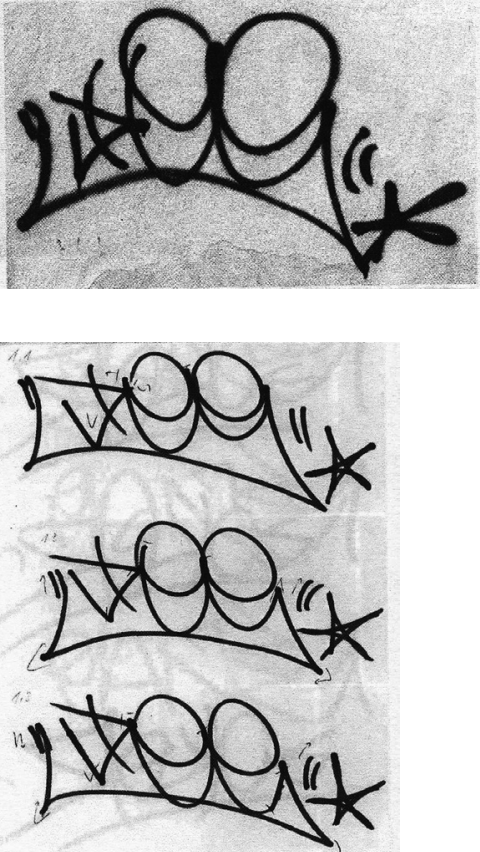
It is possible to compare general handwriting characteristics, such as fluency and speed of writing, height relationships of letters, letter proportions etc. It is difficult to analyse it with a high degree of probability, because there are some restrictions in the examination of graffitis. Usually we cannot examine the original but only a photo. Because the graffiti is big and written with a spray we cannot examine details of the structure.

Another aspect is that graffitis are written on various places, on a wall at the bottom or high up, on a subway, a car or a pane of glass. This leads to many deviations. Another aspect is the calligraphic kind of writing. All sprayers learn and exercise their art with special tags or symbols and therefore have similar movements and figures. Some symbols are easy to imitate and make it difficult to pin these forms to a special person. A result of studies is that even for professional sprayers it is difficult to imitate complex tags. These tags result from an experience. A sprayer declared he is able to copy each tag perfectly. Forensic experts show him five tags and after some time he wrote the tags from his memory. Here you see two of the tags, the tag above is the original and the other three are imitations.

The sprayer recognised very well the figure and also some details like points and stars. But forensic experts could see that the movement and direction of some lines are not the same. Therefore it seems to be possible to prove the authenticity. There are more possibilities to examine graffitis in the case they are written in letters, these graffitis are called writings.
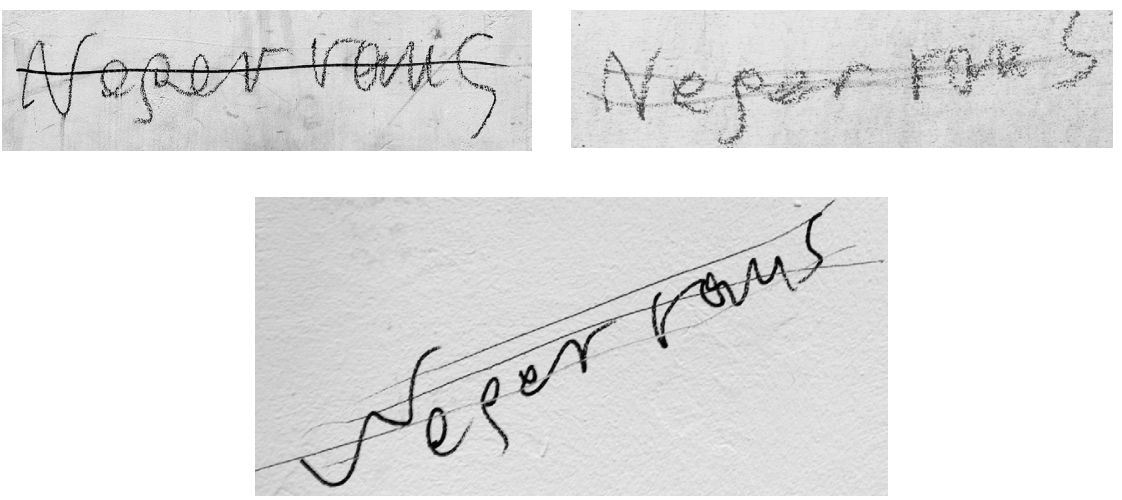

Example 1. Very similar 
The writings in example 1 are very similar in the forms and also the degree of connectedness.

The writings in example 2 are also similar, but show some differences in the letters ' $g$ ', ' $u$ ' and 's' and also in the connectedness.

Comparing block letters we can also see similarities.
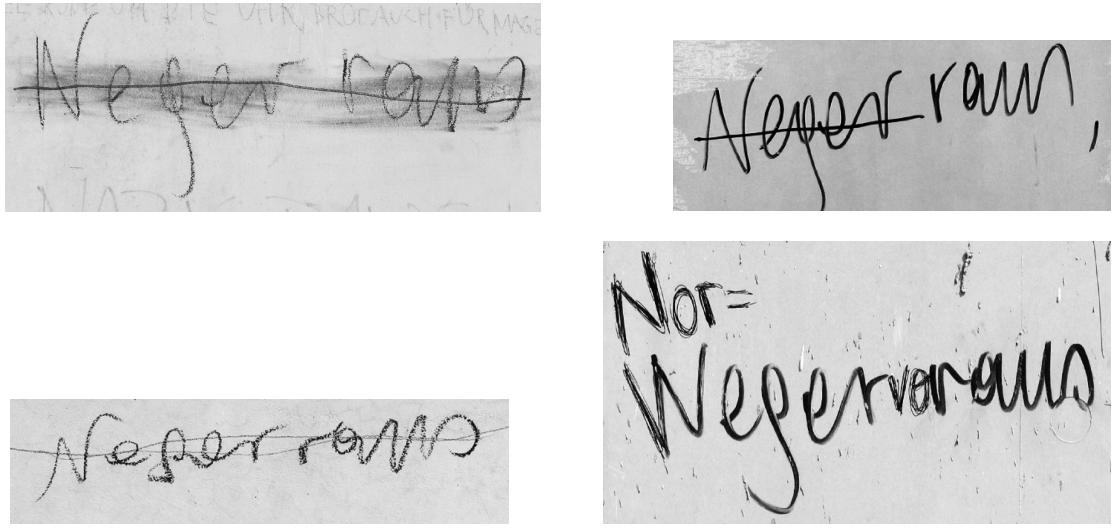

Example 2. Similar, some differences
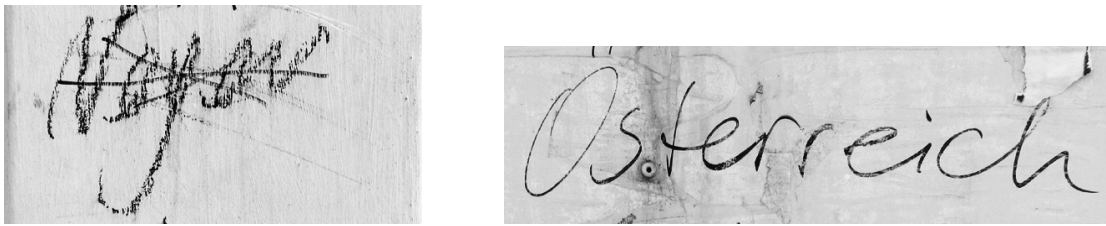

Not similar

1

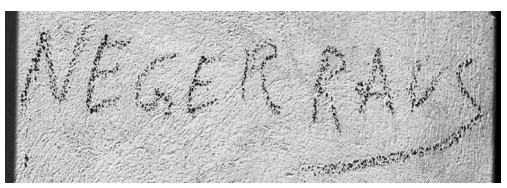

2

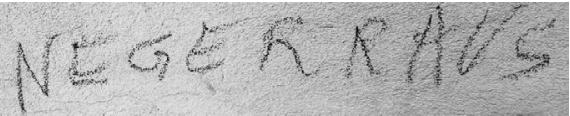

Very similar

Nowa Kodyfikacja Prawa Karnego 45, 2017

(C) for this edition by CNS 

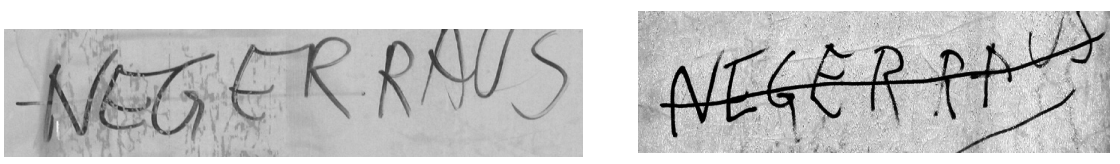

Similar
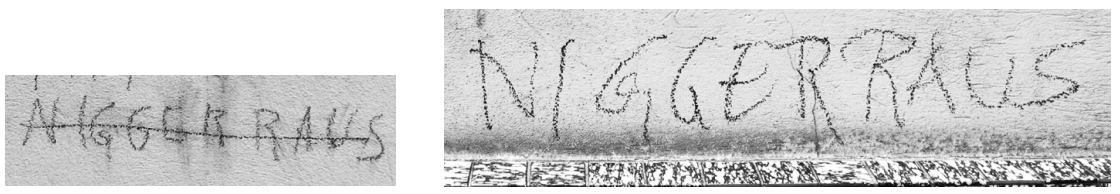

Not similar

To identify a writer it is necessary to have an original tag or an original handwriting from the person.

Suppose the tag 1 is authentic, we can declare:

The tag 2 corresponds in a very high degree with the tag 1 , this is a strong hint to the identity of both writers. The tags of the second block are similar, the identity of the writer is possible.

The other tags are not similar to tag 1. Presumably they are written from one (other) person. Now I return to the mysterious graffiti on the wall of the university.
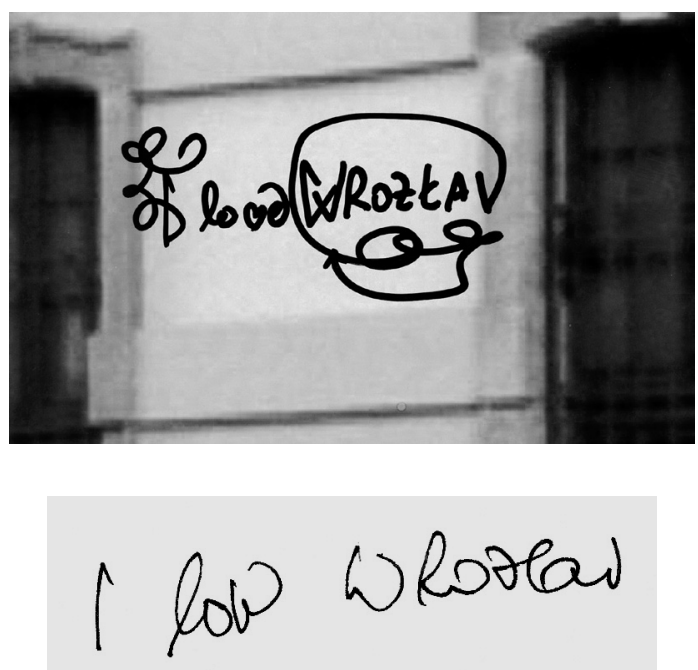
The letter ' $I$ ' in the graffiti is formed calligraphically. But still there is a small hook at the beginning corresponding with the handwriting. The word 'love' is similar in graffiti and handwriting. The word 'Wrozlav' is written in block letters and it is not possible to compare it with the handwriting. There is still a small correspondence in the letters ' $\mathrm{W}$ ' and ' $\mathrm{R}$ ', ' $\mathrm{W}$ ' with a hook and a left trend and ' $\mathrm{R}$ ' with a right trend. The letter ' $\mathrm{W}$ ' is written with crossed strokes. This form sometimes is used in Poland. Writing in this kind could be a hint that the writer is coming from Poland; also the ' $\mathrm{L}$ ' is correctly crossed. But there are two material errors. Nobody in Poland would write Wroclaw with a ' $z$ ' in the middle and a ' $v$ ' at the end. Therefore, it is evident that the writer originates from another country.

In the handwriting we see the same linguistic errors. Therefore it should be possible to say with a high degree of probability that the graffiti and the handwriting are written by the same person. In fact the graffiti and the handwriting were produced by me, as an example.

\section{References}

Graffiti world, street art aus fünf Kontinenten. Nicholas Ganz. Edition Schwarzkopf und Schwarzkopf, Berlin 2005.

Graffiti und Street Art, Edition Deutscher Kunstverlag. Berlin 2012.

Graffiti, die Sprache an den Wänden. Thomas Nordhoff. Edition Erhard Löcker GesmbH, Wien 2005.

Mannheimer Hefte für Schriftvergleichung, Heft 3+4/02. Edition Schmid Röhwild, Lübeck.

\section{Summary}

From the forensic point of view it is not easy to identify a person as an author of writing in graffiti mode, but at least in some cases it seems to be possible.

Keywords: graffiti, forensic examination of handwriting. 